\title{
21. Yüzyıl Becerileri ve Bu Becerilerin Ölçülmesinde Kullanılan Araçlar ve Yaklaşımlar
}

\begin{tabular}{lccc}
\hline MAKALE TÜRÜ & Başvuru Tarihi & Kabul Tarihi & Erken Görünüm Tarihi \\
Derleme Makalesi & 03.12 .2017 & 14.03 .2018 & 15.03 .2018 \\
\hline
\end{tabular}

Seher Yalçın

Ankara Üniversitesi

Öz

Bu çalışmada, 21. yüzyıl becerilerini tanımlamak ve onları ölçmek için kullanılan çeşitli araçları ve yaklaşımları tanıtmak amaçlanmıştır. 21. yy becerileri, temel becerileri kapsamakla birlikte; i) öğrenme ve yenilik becerileri, ii) bilgi, medya ve teknoloji becerileri ve iii) yaşam ve kariyer becerileri olmak üzere üç ana beceri alanından oluşmaktadır. Yapılan alanyazın incelemesinde, bu tür becerilerin ölçülmesinde; derecelendirme ölçekleri, durumsal yargı testleri, performans değerlendirmeler ve simülasyonlar, portfolyolar ve farklı madde türlerini içeren araçlar (çoktan seçmeli, bilgisayar destekli ve açık uçlu maddeler gibi) kullanıldığ görülmüştür. Ancak bahsedilen ölçme araçlarının ve yaklaşımlarının bazıları Türkiye'de kullanılmamaktadır. Ayrıca pek çok ülkede teknolojik gelişmelere paralel olarak bilgisayartemelli ölçme uygulamalarının kullanıldığı görülmüştür. Bilgisayar ortamı, bu yaklaşımlardan gerçek duruma dayalı bilgisayar simülasyonları gibi uygulamaların kullanılmasına izin vermekte, bu durum da hem bilişsel hem kişilerarası becerilerin gerçeğe oldukça yakın bir şekilde ölçülmesine firsat tanımaktadır. Ayrıca ders kitaplarında, öğrencilerin kişilerarası ve içsel becerilerini ortaya koymalarını sağlayacak durumsal yargı testi gibi ölçme yaklaşımlarına yer verilmesi önerilmektedir.

Anahtar sözcükler: 21. yy becerileri, ölçme, durumsal yargı testleri, bilgisayar destekli uygulamalar.

Sorumlu Yazar: Arş. Gör. Dr., Eğitim Bilimleri Fakültesi, Eğitim Bilimleri Bölümü, E-posta: yalcins@ankara.edu.tr, http://orcid.org/0000-0003-0177-6727 
Eğitimin en önemli amaçlarından biri, öğrencilerin günlük hayatlarını kolaylaştırmayı sağlamak ve onları iş dünyasına hazırlamaktır. Bu durum, aynı zamanda yüzyılın en büyük sorunlarından biri ve üzerinde çalışılması gereken bir konudur (Trilling ve Fadel, 2009). Eğer okul eğitimi ve okul diş1 öğrenme faaliyetleri, öğrencileri; gelecekteki vatandaş, çalışan, yönetici, ebeveyn, gönüllü ve girişimci gibi yetişkin rolleri için hazırlarsa, bugünkü çocuklar gelecekteki zorluklarla başa çıkabilirler. Gençlerin, yetişkin olduklarında tüm potansiyellerini ortaya çıkarmak için dil, matematik ve diğer okul konularını içeren bilişsel becerilerini ve bu konuların uygulamasını kolaylaştıracak birçok bilişsel olmayan becerilerini de geliştirmeye ihtiyaçları vardır (National Research Council, 2012).

Öğrencilerin bilişsel becerileri kadar bilişsel olmayan becerileri de önemlidir ve okul ortamında bu beceriler geliştirilebilir. Standart testlerle tipik olarak test edilen bilişsel beceriler dişındaki becerilerin önemi, yaklaşık 15 yıldır giderek artmaktadır (Kylonen, 2012). Aynı zamanda, iş dünyası ve siyasi liderler, okullardan öğrencilerin "21. yüzyıl becerileri" olarak anılan problem çözme, eleştirel düşünme, iletişim, işbirliği ve öz-yönetim gibi becerilerini geliştirmelerini istemektedir (National Research Council, 2012). Bu becerilerin okul yıllarında kazanılması, ülkelerin gelecekteki rekabet piyasasındaki yerleri için de belirleyici olduğundan özellikle gelişmekte olan ülkelerin bu duruma daha fazla önem vermesi gerektiği düşünülmektedir.

21. yüzyıl becerilerinin önemine pek çok çalışmada dikkat çekilmekle birlikte (örneğin; Eryılmaz ve Uluyol, 2015; Göksün ve Kurt, 2017; Lai ve Viering, 2012), alanyazında, 21. yüzyıl becerilerinin neler olduğu konusunda farklı görüşler vardır (Dicerbo, 2014; Kylonen, 2012; Lai ve Viering, 2012). Bu nedenle, 21. yüzy1l becerilerinin neler olduğu ve bu becerilerin kabul gören bir sınıflamasını sunmanın önemli olduğu düşünülmektedir. $\mathrm{Bu}$ becerilerin ölçülmesinde ise derecelendirme ölçekleri, durumsal yargı testleri, performans değerlendirmeler ve bilgisayar simülasyonları, beceri ve yetenek geçmişi, portfolyolar, farklı madde türlerini içeren araçlar (çoktan seçmeli, bilgisayar destekli ve açık uçlu maddeler) kullanılabilmektedir (Kylonen, 2012; Soland, Hamilton ve Stecher, 2013). Bahsedilen ölçme yaklaşımlarından bazıları (derecelendirme ölçekleri, performans değerlendirmeler, portfolyolar, çoktan seçmeli ve açık uçlu maddeler) Türkiye'de de kullanılmaktadır. $\mathrm{Bu}$ yaklaşımların kullanılma sıklığına bakıldığında, derecelendirme ölçeklerinin en sık kullanılan (\% 40.5) ölçme araçları olduğu, açık uçlu ve çoktan seçmeli maddelere dayalı başarı testlerinin düşük bir oranda (\% 5.2), performans değerlendirme ve portfolyoların ise daha düşük oranda ( $\left.\begin{array}{ll}\% & 3.2\end{array}\right)$ kullanıldığı, Eğitim ve Bilim Dergisinde 2007-2013 yılları arasında yayımlanan makalelerin incelendiği bir çalışmada tespit edilmiştir (Selçuk, Palancı, Kandemir ve Dündar, 2014). Bu çalışmada, Türkiye'de kullanılan ölçme yaklaşımlarının 21. yüzyıl becerileriyle ilişkisini göstermek ve bu yaklaşımları kullanırken dikkat edilmesi gereken noktaları vurgulamak için bu yaklaşımlar da kapsama dahil edilmiştir. Diğer ölçme yaklaşımlarından bilgisayar temelli ölçmelerin ise Türkiye'de sınırlı sayıda, dil ve ehliyet becerilerine yönelik sınavlarda (e-Yabancı 
Dil Sınavı, e-Motorlu Taşıt Sürücü Kursiyerleri Sınavı) klasik çoktan seçmeli formatta kullanıldığı görülmektedir. Durumsal yarg1 testlerinin ise personel seçme amaçlı olarak Türkiye'de sadece birkaç çalışmada (Çolakoğlu, 2013; Eriş, 2013) kullanıldığ1 görülmüştür. Ancak bahsedilen ölçme uygulamalarının, öğrencilerin 21 . yüzyıl becerilerini ölçmede kullanımına ilişkin Türkiye'de bir çalışmaya rastlanmamıştır. Ayrıca öğrencilerin sahip oldukları 21. yüzyıl becerileri ile sosyal medyadaki beceri ve yetenek geçmişine ait bilgiler arasındaki ilişkilerin ve öğrencilerin performansının değerlendirilmesinde bilgisayar simülasyonlarının kullanımına ilişkin çalışmalara da rastlanmamıştır. Bu durumun, bazı ölçme yaklaşımlarının yeterince bilinmemesinden kaynaklandığı da düşünülmektedir. 21 . yüzyıl becerilerinin, ülkelerin gelecekteki rekabet piyasasındaki yerleri açısından da okul yıllarında kazanılmasının önemi, Türkiye'de 21. yüzyıl becerilerini ölçmek için kullanılan ölçme yaklaşımlarının yetersizliği ve bazı ölçme yaklaşımlarının yeterince bilinmemesi nedenleriyle bu çalışmanın yapılmasına gerek duyulmuştur. Bu çalışmada, 21. yüzyıl becerilerini tanımlamak ve onları ölçmek için kullanılan çeşitli yaklaşımları ve araçları örneklerle tanıtmak amaçlanmıştır.

\section{Yüzyıl Becerileri}

21. yüzyıl becerilerinin neler olduğu konusunda alanyazında genel bir eğilim olmakla birlikte farklı görüşler de bulunmaktadır. Alanyazında, P21 olarak anılan 21. yüzyıl becerilerinin genel çerçevesi Şekil 1'de gösterilmiştir.

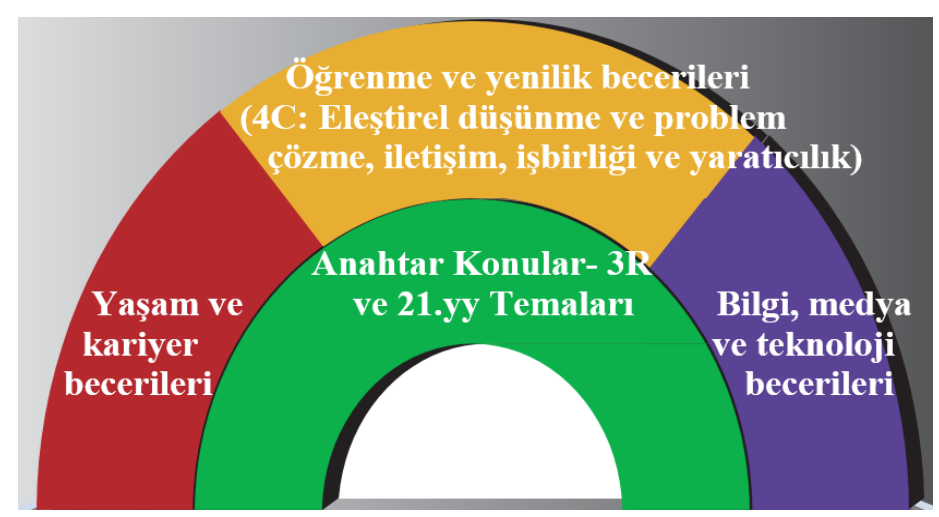

Şekil 1. 21. yüzyıl öğrenmesi için P21 çerçevesi (partnership for $21^{\text {st }}$ century learning (P21), 2007)

Şekil 1'de görüldüğü gibi, P21, temel konuları (3R'ler: İngilizce, okuma ve dil sanatları, dünya dilleri, sanat, matematik, ekonomi, bilim, coğrafya, tarih, devlet ve yurttaşlık bilgisi) içermekle birlikte, i) öğrenme ve yenilik becerileri, ii) bilgi, medya ve teknoloji becerileri ve iii) yaşam ve kariyer becerileri olarak anılan üç ana beceri 
alanından oluşmaktadır (Kylonen, 2012; Partnership for $21^{\text {st }}$ Century Learning, 2007; Trilling ve Fadel, 2009).

Şekil 1'de yer alan, öğrenme ve yenilik becerileri (4C- critical thinking, communication, collaboration, creativity); i) eleştirel düşünme ve problem çözme, ii) iletişim, iii) işbirliği ve iv) yaratıcılık olmak üzere dört beceriden oluşmaktadır (Kylonen, 2012; Partnership for $21^{\text {st }}$ Century Learning, 2007; Trilling ve Fadel, 2009). Bu beceriler, yaşam boyu öğrenmenin ve yaratıcı düşünmenin anahtarı olarak görülmektedir (Trilling ve Fadel, 2009). Facione, Sánchez, Facione ve Gainen (1995)'e göre, eleştirel düşünme; doğru analizler, çıkarımlar ve değerlendirmeler yapma ile tümevarımlı ve tümdengelimli akıl yürütmeyi içerir. Eleştirel düşünme; yargılayıcı, yansıtıcı ve amaçlıdır (Facione, Facione ve Giancarlo, 2000). Eleştirel düşünme becerisine sahip öğrenciler; i) duruma uygun olarak çeşitli akıl yürütme türlerini (tümevarım, tümdengelim vb.) kullanma, ii) karmaşı sistemlerde genel sonuçların üretilmesi için bütünün bir parçasının birbiriyle nasıl etkileşimde bulunduğunu analiz etme, iii) alternatif bakış açılarını analiz etme ve değerlendirme, iv) analiz sonuçlarına dayanarak bilgileri yorumlama ve sonuç çıkarma, v) öğrenme deneyimlerini ve süreçlerini eleştirel olarak düşünme gibi özelliklere sahip olmalıdır (Partnership for $21^{\text {st }}$ Century Learning, 2015; Trilling ve Fadel, 2009). Problem çözme ise bir hedefin gerçekleşmesi veya bir sorunun aşılması için gerekli olan zihinsel basamaklar olarak tanımlanabilir (Haladyna, 1997). Problem çözme becerisine sahip öğrenciler; bilinmeyen farklı türdeki problemleri hem geleneksel hem de yenilikçi yollarla çözmek, çeşitli bakış açılarını açıklamak ve daha iyi çözümler bulmak için kayda değer sorular sorma ve tanımlama özelliklerine sahip olmalidir.

İletişim becerisi; sözlü, yazılı ve sözsüz iletişim becerilerini çeşitli biçimlerde ve bağlamlarda etkin biçimde kullanarak düşünce ve fikirleri ifade etme, etkin bir dinleyici olma ve farklı ortamlarda (çok dilli dahil) etkin bir şekilde iletişim kurma olarak ifade edilebilir (Partnership for $21^{\text {st }}$ Century Learning, 2015; Trilling ve Fadel, 2009). İşbirliği becerisine baktığımızda, çeşitli gruplarla etkili ve saygılı bir şekilde çalışabilme becerisi göstermek, ortak bir hedefi gerçekleştirmek için gerektiğinde ödün vermeye istekli olmak ve ortak çalışma sorumluluğunu üstlenerek her ekip üyesi tarafından yapılan bireysel katkıları değerlendirebilmek olarak ifade edilebilir (Partnership for $21^{\text {st }}$ Century Learning, 2015; Trilling ve Fadel, 2009). Son olarak yaratıcılık; bir şeyleri yeni yollarla (kavramsal ya da sanatsal olarak) bir araya getirme, yeni bir şeyler inşa etme, olağandışı veya alışılmadık durumları kullanarak ilginç bir durum oluşturmak için çalışmak olarak tanımlanabilir (Brookhart, 2010). Yaratıcılık becerisine sahip öğrenciler; geniş kapsamda, bir fikir oluşturma tekniği kullanma (beyin fırtınası gibi), yeni ve değerli fikirler yaratma, yaratıcı fikirler geliştirme ve onları en üst düzeye çıkarmak için kendi fikirlerini ayrıntılı bir şekilde inceleme, analiz etme ve değerlendirme gibi özelliklere sahip olmalıdır (Partnership for $21^{\text {st }}$ Century Learning, 2015; Trilling ve Fadel, 2009). 
Bilgi, medya ve teknoloji becerileri; i) bilgi, ii) medya ve iii) bilgi ve iletişim teknolojileri okuryazarlı̆̆ını içermektedir (Kylonen, 2012; Partnership for $21^{\text {st }}$ Century Learning, 2007; Trilling ve Fadel, 2009). Dijital okuryazar olan bireylerin, karşılaşılan sorun için doğru ve yaratıcı bir şekilde bilgiyi kullanması, çok çeşitli kaynaklardan gelen bilgiden ilgili olanı seçebilmesi, bilgi erişimi ve kullanımı ile ilgili ahlaki/yasal konular hakkında temel bir anlayışa sahip olması beklenmektedir (Partnership for $21^{\text {st }}$ Century Learning, 2015; Trilling ve Fadel, 2009).

Yaşam ve kariyer becerileri ise i) esneklik ve uyumluluk, ii) girişkenlik ve kendi kendini yönetme, iii) sosyal ve kültürlerarası etkileşim, iv) üretkenlik ve hesap verebilirlik, v) liderlik ve sorumluluk becerilerinden oluşmaktadır (Kylonen, 2012; Partnership for $21^{\text {st }}$ Century Learning, 2007; Trilling ve Fadel, 2009). Bu becerilere sahip öğrencilerin sahip olmaları gereken bazı beceriler sırayla ayrıntılı olarak sunulmuştur (Partnership for $21^{\text {st }}$ Century Learning, 2015): Esneklik ve uyumluluk becerisine sahip öğrenciler; i) değişikliğe uyum sağlama, ii) değişen rollere, iş sorumluluklarına, programlara ve bağlamlara uyum sağlama, iii) övgü, başarısızlık ve eleştirileri olumlu karşılama, iv) özellikle çok kültürlü ortamlarda pratik çözümlere ulaşmak için çeşitli görüş ve düşünceleri anlama ve dengeleme özelliklerine sahip olmalıdır. Girişkenlik ve kendi kendini yönetme becerisine sahip öğrenciler; i) hedefleri ve zamanı yönetme, ii) hedefleri somut ve somut olmayan başarı kriterleri ile belirleme, iii) taktik (kısa vadeli) ve strateji (uzun vadeli) hedeflerini dengeleme, iv) bağımsız olarak çalışma, v) kendini yönlendiren öğrenenler olma, vi) yaşam boyu bir süreç olan öğrenmeye bağl1lığını gösterme özelliklerine sahip olmalıdır. Sosyal ve kültürlerarası etkileşim becerisine sahip öğrenciler; i) başkalarıyla etkili bir şekilde etkileşimde bulunma, ii) dinleme ve konuşma için uygun zamanları bilme, iii) çeşitli gruplarda etkili bir şekilde çalışma, iv) kültürel farklılıklara saygı duyma ve farklı sosyal ve kültürel geçmişe sahip kişilerle etkili bir şekilde çalışma, v) yeni fikirler yaratmak ve yenilik ve iş niteliğini artırmak için sosyal ve kültürel farklılıkları geliştirme özelliklerine sahip olmalıdır. Üretkenlik ve hesap verebilirlik becerisine sahip öğrenciler; i) projeleri yönetme, ii) amaçlanan sonuca ulaşmak için çalışmaya öncelik verme, iii) olumlu ve etik bir şekilde çalı̧̧a, iv) zamanı ve projeleri etkili bir şekilde yönetme, v) kendini profesyonelce ve uygun görgü kurallarıyla sunma, vi) gruplarla birlikte işbirliği yapma, vii) grup çeşitliliğine sayg1 gösterme ve sonuçlardan sorumlu olma özelliklerine sahip olmalıdır. Liderlik ve sorumluluk becerisine sahip öğrenciler; başkalarını bir hedefe yönlendirmek ve rehber olmak için kişilerarası beceriler ile problem çözme becerilerini kullanma, ortak bir hedefi gerçekleştirmek için başkalarının güçlerini geliştirme, etki ve güç kullanımında dürüstlük ve etik davranış sergileme ile başkalarına karşı sorumlu davranma özelliklerine sahip olmalıdır.

21. yüzyıl becerilerinin ayrıca, bilişsel beceriler (ör., eleştirel düşünme, problem çözme, yaratıcılık), kişilerarası beceriler (iletişim becerileri, sosyal beceriler, ekip çalışması, kültürel duyarlılık, zorluklarla baş etme) ve içsel (intrapersonal) beceriler (öz yönetim, öz düzenleme, zaman yönetimi, kişisel gelişim, yaşam boyu öğrenme, uyumluluk) olarak sınıflandırıldığı da görülmektedir 
(Binkley, Erstad, Herman, Raizen ve Ripley, 2010; Kylonen, 2012; Soland ve diğ., 2013). Bu sınıflandırmanın becerilerin nasıl değerlendirileceği konusunda çerçeve oluşturmaya yardımcı olduğu ifade edilmektedir (Kylonen, 2012). Bilişsel beceriler, okullaşma yoluyla geliştirilen, genellikle hesap verebilirlik testinde kullanılanlar gibi standart testlerle kolayca ölçülen, geniş ölçekli ulusal (Yükseköğretime Geçiş Sınavı-YGS, Liseye Geçiş Sınavı-LGS) ve uluslararası (The Program for International Student Assessment-PISA, Trends in International Mathematics and Science Study-TIMSS) değerlendirmelerde, örneğin, matematik ve dil becerileri gibi içerik alanlarında geliştirilen beceriler anlamına gelmektedir. Bilişsel olmayan beceriler ise okullaşma yoluyla geliştirilen ve bilişsel test puanlarına yansımayan diğer tüm becerileri ifade etmektedir (Kylonen, 2012).

\section{Yüzyıl Becerilerinin Ölçülmesi}

21. yüzyıl becerilerinin neler olduğu ve geliştirilmesi önemli olduğu kadar nasıl ölçüleceği ve değerlendirileceği de bir diğer önemli husustur. Şimdiye kadar ki ölçme uygulamaları (çoktan seçmeli, açık uçlu vb.), 21. yüzyıl becerilerini ölçmek için yeterli değildir. Bu becerilerin ölçülmesi ve değerlendirilmesi, var olan ölçme ve değerlendirme yaklaşımlarından farklı yaklaşımlar gerektirebilmektedir. Örneğin, çoktan seçmeli, kısa, yapılandırılmış yanıt veya kompozisyon (essay) testleri; grup çalışması, işbirliği, liderlik ve iletişim gibi kişilerarası beceriler veya yaratıcılık gibi bazı zor bilişsel becerilerin ölçülmesinde yeterli olmayabilmektedir (Kylonen, 2012). Alanyazın incelemesinde, bu tür becerilerin ölçülmesinde; derecelendirme ölçekleri, durumsal yargı testleri, performans değerlendirmeler ve simülasyonlar, beceri ve yetenek geçmişi, portfolyolar, farklı madde türlerini içeren araçlar (çoktan seçmeli, bilgisayar destekli ve açık uçlu maddeler) kullanılabildiği görülmektedir (Kylonen, 2012; Soland ve diğ., 2013). Ancak bahsedilen ölçme araç ve yaklaşımlarından bazılarının (durumsal yargı testleri, performans değerlendirme ve simülasyonlar, beceri ve yetenek geçmişi, bilgisayar destekli maddelerin yer aldığ 1 uygulamalar) Türkiye'de yaygın olarak kullanılmadığ 1 belirlenmiştir. Türkiye'de kullanılan ölçme yaklaşımlarının da 21. yüzyıl becerileriyle ilişkisini göstermek ve bu yaklaşımları kullanırken dikkat edilmesi gereken noktaları vurgulamak amacıyla bu tür becerileri ölçme yaklaşımları, kullanılan araçlar ve örnek maddelere ilişkin bilgiler; belirtilen tüm yaklaşımlar için aşağıda sırayla sunulmuştur.

\section{Derecelendirme Ölçekleri}

Likert türü öz bildirim maddeleri, 21. yüzyıl yeterliklerini ölçmek için çoğunlukla kullanılan bir ölçme yaklaşımıdır (Soland ve diğ., 2013). Likert türü maddeler, kişilerarası ve içsel becerileri ölçmek için kullanılan en popüler yoldur. $\mathrm{Bu}$ maddelerle yapılan ölçmelerde, birey hakkında hem kendisi hem de başkaları (öğretmenler vb.) tarafından derecelemeler yapılabilmektedir (Kylonen, 2012). Bu tür ölçmelere örnek olarak PISA 2012 öğrenci anketinde, öğrencilerin matematik başarısında algılanan kontrolü belirlemek için yer alan maddelerden biri verilebilir: "Yeterli çaba sarf edersem, matematikte başarılı olurum." Bu madde "kesinlikle katılmıyorum, katılmıyorum, katılıyorum, kesinlikle katılıyorum” şeklinde 
derecelendirilmiştir. Öğrenciler kendilerine uygun olan dereceyi seçerek yanıt vermektedir (OECD, 2013).

Likert türü maddeleri kullanırken dikkat edilmesi gereken bazı durumlar vardır. Bunlardan ilki, likert türü maddelerde kullanılan derecelemelerle ilgilidir. Bu derecelemeler, farklı bireyler için farklı şeyler ifade edebilir. Bu durum, sonuçların yorumlanmasını güçleştirmektedir. Derecelendirme ölçeklerinin öznelliğinden kaçınmak için davranışsal olarak ankorlanmış derecelendirme ölçekleri kullanılmaktadır (Kylonen, 2012). Diğer dikkat edilmesi gereken durum, likert türü maddeler ile yapılan ölçmelerde, tepki stili problemleridir (Harzing, 2006; Liu, Lee ve Conrad, 2015; Lu ve Bolt, 2015). Likert türü ölçmelerin geçerliğini arttırmak ve öznel derecelendirme problemlerini gidermek için "anchoring vignette" yaklaşımı kullanılmaktadır (Hopkins ve Kings, 2010; Kylonen, 2012; OECD, 2014). Bu yaklaşımda, öğrencilerden ilgili maddeleri derecelendirmeden önce, maddeler için oluşturulan ortak vignet setlerini (ankor olarak hizmet eden) derecelendirmeleri istenmektedir. Sonra öğrencilerin bu vignetlere verdikleri tepkilere dayanarak asıl maddelere verdikleri tepkiler ölçeklenmektedir (Kylonen ve Bertling, 2012; OECD, 2014). Bireyler arasında derecelendirmelerin karşılaştırılabilirliğini artırmak için tasarlanan bir diğer yöntem, zorunlu seçimdir (forced choice). Burada kastedilen, örneğin bir öğrenciye beşli Likert türü bir ölçekte matematiği ne kadar çok sevdiğini sormak yerine, öğrenciye matematik, fen veya dil alanlarından hangisini daha çok sevdiğinin sorulduğu bir tekniktir (Kylonen, 2012).

\section{Durumsal Yargı Testleri (DYT)}

Likert türü maddelerle yapılan ölçmelerde, kültürler arası karşıısştırılabilirlik ve tepki stillerinin etkilerine ilişkin sorunları azalttı̆̆ için likert türü maddelerin yerine durumsal yargı testleri tercih edilmektedir (OECD, 2015). İşe eleman almada ve endüstride sıklıkla kullanılan DYT'lerde tepkiler, genelde çoktan seçmeli ya da likert türünde olmaktadır (Kylonen, 2012). DYT, işle ilgili durumlar ve durumlara olası tepkiler sunularak bireylerin seçim yapmalarının istendiği bir testtir (McDaniel, Hartman, Whetzel ve Grubb, 2007). Bireylerin içsel becerilerini ölçmek için yaygın olarak kullanılmakla birlikte grup çalışması, iletişim gibi ölçülmesi zor 21. yüzyıl becerilerinin ölçülmesinde de kullanılmaktadır (Kylonen, 2012).

McDaniel ve Nguyen (2001), DYT tepki yönergelerini/talimatlarını, bilgiye dayalı ve davranış eğilimi olmak üzere iki kategoride ele almışlardır. Bilgiye dayalı tepki yönergeleri, katılımcılardan doğru veya mümkün olan en iyi cevabı seçmesini veya tepkilerin etkinliğini değerlendirmesini istemektedir. Davranış eğilimi tepki yönergeleri, katılımcının, muhtemelen ne yapacağını temsil eden yanıtı seçmesini ya da bir eylem gerçekleştirme ihtimalini değerlendirmesini istemektedir. McDaniel ve Nguyen (2001) tepki yönergelerinin yap1 ve ölçüt dayanaklı geçerliği etkileyebileceğini ifade etmektedir. Ayrıca sahte (faking) yanıtlama davranışının DYT'nin yüksek riskli test durumlarında kullanımı için olası bir tehdit olduğundan, dikkate alınması gerektiği belirtilmektedir (Peeters ve Lievens, 2005). Durumsal 
yargı testine örnek olarak PISA 2012 öğrenci anketindeki bir madde alınmıştır (OECD, 2014):

Cep telefonunuzdan birkaç hafta boyunca kisa mesaj gönderdiğinizi varsayalım. Ancak bugün, kisa mesaj gönderemediniz. Sorunu çözmeye çalışmak istiyorsunuz.

Ne yapardinız? Her öneri için, sizin için en uygun seçeneği işaretleyin. (Lütfen her bir satırda yalnızca bir kutuyu işaretleyin) "1. Bunu kesinlikle yapardim, 2. Muhtemelen bunu yapardım, 3. Muhtemelen bunu yapmazdım, 4. Kesinlikle bunu yapmazdım"

a) Neyin yanlı̧̧ olduğunu anlamak için mümkün olan her düğmeye basarım.

b) Soruna neden olabilecekleri ve sorunu çözmek için ne yapabileceğimi düşünürüm.

c) El kitabinı okurum.

d) Bir arkadaşımdan yardım isterim.

\section{Performans Değerlendirmeler ve Simülasyonlar}

Performansın değerlendirilmesinde, gerçek yaşam durumuna ilişkin bireylerin tepkileri alınır. Örneğin, iletişim ve işbirliği performansının değerlendirilmesinde, ögrencilerden akranlarına ve öğretmenlerine bir grup sunumu yapmaları istenebilir ve akran ve/veya öğretmenleri tarafindan puan verilir (Soland ve diğ., 2013). Performans değerlendirmesi veya simülasyona bir örnek, PISA'nın işbirliğine dayalı problem çözmeyi (IPÇ) ölçen yeni bir kısmı verilebilir (OECD, 2017; Soland ve diğ., 2013). PISA 2015 uygulamasında yer alan örnekte, öğrenciler, takım arkadaşları ile etkili bir biçimde karşılıklı yazışma ile bir durumu çözme yetenekleri konusunda yargılanır. Sınava giren kişi, sorunun ortak bir şekilde anlaşılmasını sağlayarak, yanlış anlamaları açıklığa kavuşturarak ve gerçekleştirilecek eylemler hakkında ekip üyesiyle fikir birliği oluşturarak İPÇ becerilerini gösterir. Giriş ve yönlendirme, senaryonun taslağı üzerine bir ön bilgi (brifing) ile başlar ve ekranın "Sohbet, Kontrol Paneli ve Görev Alanı" alanlarında eğitim verilir. PISA 2015'te yer alan İPÇ’yi ölçen maddelerden birine ilişkin ekran görüntüsü Şekil 2'de verilmiştir (OECD, 2017).

Şekil 2'de görüldüğü gibi, öğrenci, verilen görevin çözümü için yazılı sohbet yoluyla işbirliği yaparak problemi çözme denemelerinde bulunmaktadır. Ayrıca öğrencilerin yaptığ 1 denemelerin sonuçlarına ilişkin de ekranda geri bildirim bulunmaktadır. $\mathrm{Bu}$ durum aynı zamanda öğrenciler için öğrenmelerin de gerçekleşmesine firsat vermektedir. 


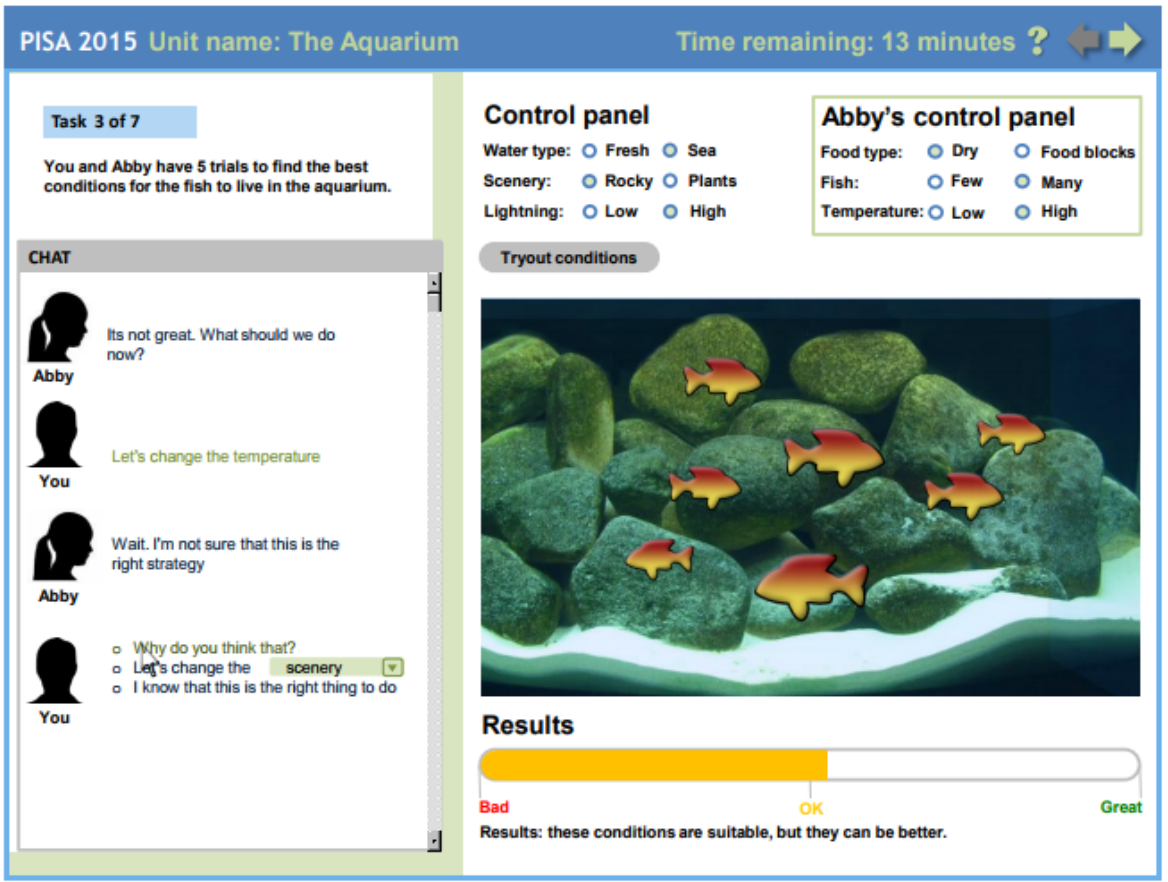

Şekil 2. PISA 2015'teki akvaryum başlıklı İPÇ becerisi için bir ekran görüntüsü (OECD, 2017)

\section{Beceri ve Yetenek Geçmişi (Biodata)}

Beceri ve yetenek geçmişi, bir öğrencinin bazı alanlarda gösterdiği yetkinliği veya elde ettiği beceriye kanıt sağlayan faaliyetlerin (biyografik veya biyofaaliyetler) toplanması anlamına gelmektedir. Bunun için sosyal medyadan edinilen bilgiler kullanılabilmektedir. Facebook, Linkedin, Twitter, Google+ ve MySpace de dahil olmak üzere sosyal medyadan edinilen beceri ve yetenek geçmişi bilgileri "büyük veri" tarama teknolojisi yardımıyla elde edilebilmektedir (Kylonen, 2012). Öğrencilerin beceri ve yetenek geçmişi, özellikle yaşam ve kariyer becerilerini ölçmede kullanılabilmektedir. Öğrencileri tanımlamak ve öğrencilerin 21. yüzyıl becerileri hakkında bilgi elde edebilmek için öğrencilerin beceri ve yetenek geçmişinin kullanıldığı bir çalışmada, öğrencilerin akılda tutma kaygıları ile kavramsal olarak ilişkili birkaç boyut (ör., uyumluluk ve sebatkarlık) ele alınmıştır. Analizler sonucu, öğrencilerin yetenek ve beceri geçmişine ilişkin ölçümlerinin tahmin edilen önemli davranışsal ve duyuşsal sonuçlarla ilişkili olduğu görülmüştür (Schmitt ve diğ., 2007). 


\section{Portfolyolar}

Öğrenci çalışmalarının belirlenen ölçütlere göre puanlanarak değerlendirildiği portfolyolarda, puanlayıcı-içi ve puanlayıcılar-arası tutarlılığın sağlanması, belirlenen ölçütlerin yapılandırma durumuna bağlıdır. Bilginin uygulanması, iletişim, işbirliği ve öğrenmeyi öğrenme gibi becerilerin gelişiminde portfolyolar kullanılabilmektedir. Ayrıca portfolyolar, öğrencilerin kendi gelişimini görmesine firsat vermektedir (Soland ve diğ., 2013).

\section{Farklı Madde Türlerini İçeren Uygulamalar}

Çoktan seçmeli maddeler. Geleneksel ölçme yaklaşımlarından çoktan seçmeli maddelerin öğrencilerin 21. yüzyıl becerilerinden eleştirel düşünme, işbirliği gibi becerilerini ölçmede kullanıldığı görülmüștür. Örneğin, Raven'in Standart Progresif Matrisler Testi'nde, bir parçası eksik olan desenlerin resimlerini göstererek eksiği bulmasının istendiği sorular çoktan seçmelidir. California Eleştirel Düşünme Becerileri Testi (CCTST)'nde (bilgisayar destekli olarak uygulanmaktadır) yer alan soruların da çoğu çoktan seçmeli türdedir. Ayrıca çoktan seçmeli maddeler durumsal yargı testlerinde de kullanılmaktadır. Çoktan seçmeli maddelerin öğrencilerin işbirliği becerilerini ölçmek için "Mission Skills Assessment (MSA)"de kullanıldığı görülmektedir (Soland ve diğ., 2013).

Kapalı uçlu bilgisayar destekli maddeler. Bilgisayarlar, karmaşık madde türlerinin kullanılmasına firsat vermekle birlikte kapalı uçlu bilgisayar destekli maddelerde, öğrencilerin kendi cevaplarını oluşturmalarına izin verilmekte ancak kendi yanıtlarını girmek yerine maddeleri seçmek veya ekranda taşımak gibi oldukça kısıtlı şekillerde cevaplarını oluşturmaktadırlar (Soland ve diğ., 2013). Bu durum çoktan seçmeli maddelerdeki şans başarısının azalmasına firsat vermektedir. Üniversiteye Hazırlık ve Kariyer Değerlendirme Ortaklığı (The Partnership for Assessment of Readiness for College and Careers-PARCC), hem performans görevlerini hem de makine ile puanlanan değerlendirme görevlerini kullanarak öğrencinin öğrenmesini ölçmek için yenilikçi bir değerlendirme sistemi geliştirmiştir. Kapalı uçlu bilgisayar destekli maddeler, PARCC uygulamasında sıklıkla tercih edilen bir türdür. Aşağıda PARCC'dan örnek bir matematik maddesi verilmiştir (http://www.ccsstoolbox.com/parcc/PARCCPrototype_main.html). 
Anne's family trip (grade 7)

About the task CCSSM Alignment Part a Part b Part c Scoring

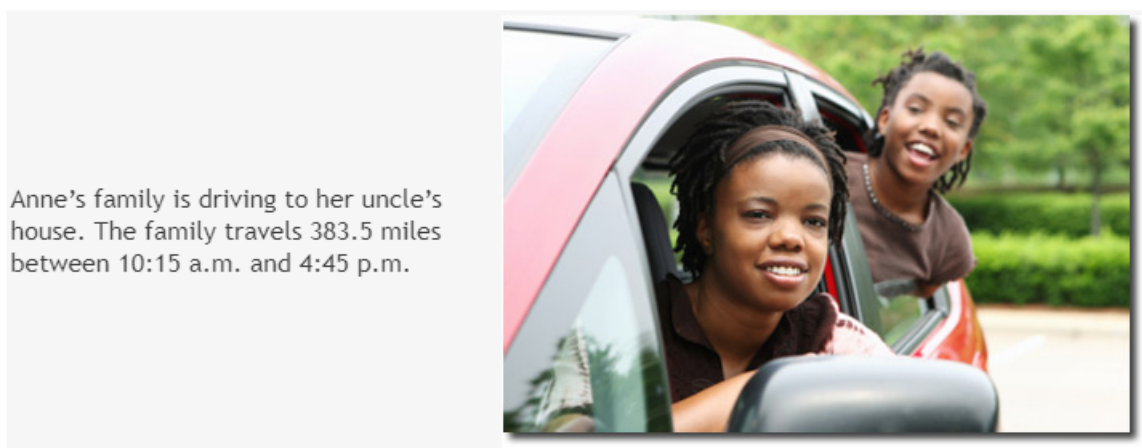

What is an equation that Anne can use to determine their average rate of travel for the day, $R$, in miles per hour? Drag the tiles to complete an equation.

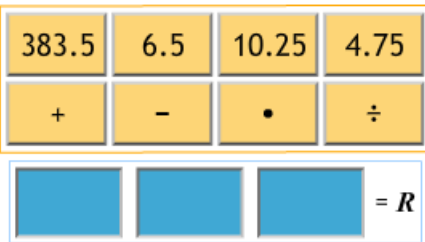

Şekil 3. PARCC'den örnek bir madde

(http://www.ccsstoolbox.com/parcc/PARCC Prototype_main.html adresinden alınd1)

Şekil 3'te yer alan örnek madde, yedinci sınıf öğrencilerinin rasyonel sayıları içeren bağlamsal bir sorunu anlamalarını ve çözmelerini gerektirmektedir. Görevde, öğrenciler, oran ve geçen süreyi içeren bir sorunu çözmek için önceki bilgilerinden de (ondalık sayı işlemleri) yararlanmaktadır.

Açık uçlu maddeler. Geleneksel olarak en yaygın kullanılan ölçme yaklaşımlarından biridir. Açık uçlu maddeler, 21. yüzyıl becerilerinden rutin olmayan problem çözmeyi ve yaratıcılığı ölçmek için özellikle uygundur. Örneğin Graduate Record Examination (GRE) sinavında, öğrencilere bir soru sorularak yapılandırılmış bir makale yazmaları istenmektedir (Soland ve diğ., 2013). Bu tür maddeler, öğrenciden öğrenciye değişen yanıtlara sahiptir.

\section{Tartışma ve Sonuç}

$\mathrm{Bu}$ çalışmada, 21. yüzyıl becerilerini tanımlamak ve onları ölçmek için kullanılan çeşitli araçları ve yaklaşımları tanıtmak amaçlanmıştır. Bu amaçla, alanyazın taranmış, 21. yüzyıl becerilerinin neler olduğu konusunda genel bir eğilim olmakla birlikte farklı görüşler olduğu da görülmüştür. 21. yüzyıl becerilerinin en 
fazla kabul gören sınıflaması şu şekildedir: 21. yüzyıl becerileri, temel becerileri kapsamakla birlikte; i) öğrenme ve yenilik becerileri, i) bilgi, medya ve teknoloji becerileri ve iii) yaşam ve kariyer becerileri olmak üzere üç ana beceri alanından oluşmaktadır (Kylonen, 2012; Partnership for $21^{\text {st }}$ Century Learning, 2007; Trilling ve Fadel, 2009). Bu ana becerilerden öğrenme ve yenilik becerileri; i) eleştirel düşünme ve problem çözme, ii) iletişim, iii) işbirliği ve iv) yaratıcılık olmak üzere dört beceriden oluşmaktadır. Bilgi, medya ve teknoloji becerileri i) bilgi, ii) medya ve iii) bilgi ve iletişim teknolojileri okuryazarlığını içermektedir. Yaşam ve kariyer becerileri ise i) esneklik ve uyumluluk, ii) girişkenlik ve kendi kendini yönetme, iii) sosyal ve kültürlerarası etkileşim, iv) üretkenlik ve hesap verebilirlik, v) liderlik ve sorumluluk becerilerinden oluşmaktadır (Kylonen, 2012; Partnership for $21^{\text {st }}$ Century Learning, 2007; Trilling ve Fadel, 2009).

Yapılan alanyazın incelemesinde ve uygulamalarda, Türkiye'de sık kullanılan ölçme ve değerlendirme yaklaşımlarının (derecelendirme ölçekleri, açık uçlu ve çoktan seçmeli maddelere dayalı başarı testleri, performans değerlendirme ve portfolyolar) genellikle öğrencilerin 21. yüzyıl becerilerinin ölçülmesi ve değerlendirilmesinde kullanılmadığı görülmektedir. Ayrıca 21. yüzyıl becerilerinin ölçülmesi ve değerlendirilmesinde bu yaklaşımların tek başına yeterli olmadığ açıktır. Bu tür becerilerin ölçülmesinde; durumsal yarg1 testleri, bilgisayar simülasyonları ve bilgisayar destekli maddeler, beceri ve yetenek geçmişi gibi ölçme araç ve yaklaşımlarının Türkiye'de sıklıkla kullanılmamasının yeterince bilinmemesinden de kaynaklı olduğu düşünülmektedir. Pek çok ülkede, teknolojik gelişmelere paralel olarak bilgisayar temelli ölçme uygulamalarına geçilmiştir. Bilgisayar teknolojisindeki gelişmeler ve internetin yaygınlaşmasıyla, sosyal medyadan edinilen beceri ve yetenek geçmişine ilişkin bilgilerin (Kylonen, 2012; Schmitt ve diğ., 2007) ve bilgisayar simülasyonları ile bilgisayar destekli maddelerin, ölçme uygulamalarında yaygınlaştı̆̆ı görülmektedir (OECD, 2017; Soland ve diğ., 2013). Bilişsel becerilerin ölçülmesinde; performans değerlendirmeler ve simülasyonlar, farklı madde türlerini içeren uygulamalar (çoktan seçmeli, bilgisayar destekli ve açık uçlu maddeler) kullanılabilmektedir. Kişilerarası becerilerin ölçülmesinde; likert türü maddeler, durumsal yargı testleri, performans değerlendirmeler ve simülasyonlar, beceri ve yetenek geçmişi, portfolyolar ve çoktan seçmeli maddeler tercih edilebilir. İçsel/kendine dönük becerilerin ölçülmesinde ise, likert türü maddeler, durumsal yargı testleri, beceri ve yetenek geçmişi ve portfolyo gibi ölçme araç ve yaklaşımları kullanılabilmektedir.

Yukarıda bahsedilen ölçme araç ve yaklaşımları tercih edilirken dikkat edilmesi gereken durumlar da söz konusudur. Bu ölçme araç ve yaklaşımları da geçerlik ve güvenirlik açısından bazı dezavantajlara sahip olabilmektedir. Örneğin likert türü maddelerde kullanılan derecelemeler, farklı insanlar için farklı şeyler ifade edebilir. Derecelendirme ölçeklerinin öznelliğinden kaçınmak için davranışsal olarak ankorlanmış derecelendirme ölçekleri kullanılmaktır (Kylonen, 2012). Ayrıca likert türü maddeler ile yapılan ölçmelerde, tepki stili problemleri ortaya çıkabilmektedir (Harzing, 2006; Liu, Lee ve Conrad, 2015; Lu ve Bolt, 2015). Likert 
türü ölçmelerin geçerliğini arttırmak ve öznel derecelendirme problemlerini gidermek için "anchoring vignette" yaklaşımı kullanılmaktadır (Hopkins ve Kings, 2010; Kylonen, 2012; OECD, 2014). Bireyler arasinda derecelendirmelerin karşılaştırılabilirliğini artırmak için tasarlanan bir diğer yöntem, zorunlu seçimdir (Kylonen, 2012). Likert türü maddelerle yapılan ölçmelerde, kültürler arası karşılaştırılabilirlik ve tepki stillerinin etkilerine ilişkin sorunları azalttığı için likert türü maddelerin yerine durumsal yarg1 testleri tercih edilmektedir (OECD, 2015). Ancak sahte yanıtlama davranışı, yüksek riskli test durumları için olası bir tehdit olduğundan DYT kullanımında dikkate alınması gerektiği de belirtilmektedir (Peeters ve Lievens, 2005). Bu bağlamda, eğiticiler ve araştırmacıların kullanmak istedikleri ölçme araçlarının ve yaklaşımlarının varsa dezavantajlarını da göz önünde bulundurarak tercih yapmaları ve kullanmaları önerilmektedir.

Teknolojik gelişmelerle, öğrencilerin kazanması gereken bilgi ve beceriler artmakla birlikte ölçme ve değerlendirme araçları ve yaklaşımları da değişmektedir. $\mathrm{Bu}$ bağlamda, öğretmenlere ve öğretmen adaylarına öğrencilerin sahip olmas1 gereken 21. yüzyıl becerilerinin neler olduğu ve bu becerileri ölçmede kullanabilecekleri araçlar ve yaklaşımlar hakkında eğitim verilmelidir. Ölçme sonuçlarına dayanarak da öğrencilerin varsa eksik yönlerini geliştirmeye yönelik sınıf içi etkinlikler, araştırma ödevleri, grup çalışmaları vb. etkinlikler verilebilir. Milli Eğitim Bakanlığı (MEB), hazırladığ 1 ders kitaplarının ölçme ve değerlendirme alanlarında, geleneksel çoktan seçmeli türde maddelerden farklı yaklaşımlara yer vermelidir. Burada kastedilen çoktan seçmeli maddelerin kullanılmaması değildir. Eleştirel düşünme ve işbirliği gibi üst düzey becerileri ölçen çoktan seçmeli maddeler de ders kitaplarında yer almalıdır. Ayrıca öğrencilerin, kişilerarası ve içsel becerilerini ortaya koymalarını sağlayacak durumsal yarg1 testleri gibi ölçme yaklaşımlarına ders kitaplarında yer verilmesi önemlidir. MEB'in yaptığı sınavlarda ve okul kitaplarında yer alan madde türleri, ölçme yaklaşımları değiştikçe, öğrenci ve öğretmenlerin de yeni madde türlerinde kendilerini geliştireceği düşünülmektedir. Ayrıca, teknolojik gelişmelere paralel olarak MEB, ölçme ve değerlendirme uygulamalarını bilgisayar sistemine taşımalı, bilgisayar temelli sistemlerin sunduğu avantajlardan faydalanarak ölçme ve değerlendirme uygulamalarını yapmalıdır. Bilindiği gibi 2015 yılı PISA uygulaması bilgisayar temelli olarak yapılmış ve öğrencilerin tüm alanlarda başarı düşüşünde, uygulamanın ilk defa bilgisayar temelli olması ve öğrencilerin bilgisayar okuryazarlık düzeylerinin temel becerilerini olumsuz etkilemiş olabileceği ifade edilmiştir (Taş, Arıcı, Ozarkan ve Özgürlük, 2016). Bu bağlamda, MEB'in yaptığ 1 ölçme ve değerlendirmelerin bilgisayar temelli olması, öğrencilerin bilgisayar okuryazarlığının gelişmesine katkı sağlayacağı düşünülmektedir. Ayrıca bilgisayar ortamı, gerçek duruma dayalı bilgisayar simülasyonları gibi uygulamaların kullanılmasına izin vermekte, bu durum da hem bilişsel hem kişilerarası becerilerin gerçeğe oldukça yakın bir şekilde ölçülmesine firsat vermektedir. Son olarak öğrenciler arası işbirliğini ve iletişimi desteklemek için okul kütüphanelerinde, öğrencilerin karşılıklı iletişim ve işbirliği ile sesli olarak çalışabilecekleri çalışma alanlarının da yer alması önerilmektedir. 


\section{Kaynakça}

Binkley, M., Erstad, O., Herman, J., Raizen, S., Ripley, M., and Rumble, M. (2010). Defining 21st century skills. White Paper commissioned for the Assessment and Teaching of 21st Century Skills Project (ATC21S). Melbourne, Australia: Assessment and Teaching of 21st Century Skills. https://www.intel.com.tr/content/dam/www/public/emea/tr/tr/pdf/education/too ls-and-resources/century21-skills-report.pdf adresinden alınd1.

Brookhart, S. M. (2010). Assess higher-order thinking skills in your classroom. Alexandria, VA: ASCD.

Çolakoğlu, Z. R. (2013). Establishing the validity of a leadership based situational judgment test. Yayımlanmamış Yüksek lisans tezi, Orta Doğu Teknik Üniversitesi, Sosyal Bilimler Enstitüsü, Ankara.

DiCerbo, K. (2014). Assessment and teaching of 21 st century skills. Assessment in Education: Principles, Policy and Practice, 21(4), 502-505. doi: 10.1080/0969594X.2014.931836

Eriş, A. (2013). Situational judgment tests in assessing specific personality characteristics. Yayımlanmamış Yüksek lisans tezi, Orta Doğu Teknik Üniversitesi, Sosyal Bilimler Enstitüsü, Ankara.

Eryılmaz, S. ve Uluyol, Ç. (2015). 21. yüzyıl becerileri sşı̆̆ında FATİH projesi değerlendirmesi. Gazi Eğitim Fakültesi Dergisi, 35(2), 209-229.

Facione, P. A., Sánchez, C. A., Facione, N. C. and Gainen, J. (1995). The Disposition toward critical thinking. Journal of General Education, 44(1), 125.

Facione, P. A., Facione, N. C., and Giancarlo, C. A. (2000). The disposition toward critical thinking: Its character, measurement, and relationship to critical thinking skill. Informal Logic, 20(1), 61-84.

Göksün, D. O. ve Kurt, A. A. (2017). Öğretmen adaylarının 21. yüzyıl. öğrenen becerileri kullanımları ve 21. yüzyıl. öğreten becerileri kullanımları arasındaki ilişki. Ĕgitim ve Bilim, 42(190), 107-130.

Haladyna, T. M. (1997). Writing test item to evaluate higher order thinking. USA: Allyn and Bacon.

Harzing, A. (2006). Response styles in cross-national survey research: A 26-country study. International Journal of Cross Cultural Management, 6(2), 243-266.

Hopkins, D. J. and King, G. (2010). Improving anchoring vignettes: Designing surveys to correct for interpersonal incomparability. Public Opinion Quarterly, $74,201-220$. 
Kylonen, P. C. (2012). Measurement of 21st century skills within the common core state standards. Paper presented at the Invitational Research Symposium on Technology Enhanced Assessments, May 7-8.

Kylonen, P. C. and Bertling, J. P. (2014). Innovative questionnaire assessment methods to increase cross-country comparability. In L. Rutkowski, M. Von Davier, and D. Rutkowski (Eds.), Handbook of international large scale assessment: Background, technical issues, and methods of data analysis (s.277-285). Boca Raton, FL.: CRC Press.

Lai, E. R. and Viering, M. (2012). Assessing 21st century skills: Integrating research findings. Vancouver, B.C.: National Council on Measurement in Education.

Liu, M., Lee, S. and Conrad, F. G. (2015). Comparing extreme response styles between agree-disagree and item-specific scales. Public Opinion Quarterly, 79(4), 952-975.

Lu, Y., and Bolt, D. M. (2015). Examining the attitude-achievement paradox in PISA using a multilevel multidimensional IRT model for extreme response style. Large-scale Assessments in Education, 3(2), 1-18. doi: 10.1186/s40536015- 0012-0

McDaniel, M. A., Hartman, N. S., Whetzel, D. L. and Grubb, W. L. (2007). Situational judgement tests, response instructions, and validity: A metaanalysis. Personnel Psychology, 60, 63-91.

McDaniel, M. A., and Nguyen, N. T. (2001). Situational judgment tests: A review of practice and constructs assessed. International Journal of Selection and Assessment, 9, 103-113.

National Research Council. (2012). Education for life and work: Developing transferable knowledge and skills in the 21st century. Committee on Defining Deeper Learning and 21st Century Skills, James W. Pellegrino and Margaret L. Hilton, Editors. Board on Testing and Assessment and Board on Science Education, Division of Behavioral and Social Sciences and Education. Washington, DC: The National Academies Press.

Organization for Economic Cooperation and Development (OECD). (2013). Ready to learn: Students' engagement, drive and self-beliefs- Volume III. Paris: OECD Publishing. http://www.oecd.org/pisa/keyfindings/PISA2012-Vol3Chap3.pdf adresinden alınd1.

OECD. (2014). PISA 2012 technical report. Paris: OECD Publishing. https://www.oecd.org/pisa/pisaproducts/PISA\%202012\%20Technical\%20Repo rt_Chapter\%2017.pdf adresinden alınd1. 
OECD. (2015). Beyond PISA 2015: A longer-term strategy of PISA. Paris: OECD Publishing. https://www.oecd.org/pisa/pisaproducts/Longer-term-strategy-ofPISA.pdf adresinden alınd1.

OECD. (2017). PISA 2015 collaborative problem-solving framework. Paris: OECD Publishing.https://www.oecd.org/pisa/pisaproducts/Draft\%20PISA\%202015\% 20Collaborative\%20Problem\%20Solving\%20Framework\%20.pdf adresinden alındı.

Partnership for 21st Century Learning (P21). (2007). Framework for 21st century learning. http://www.p21.org/our-work/p21-framework adresinden alınd1.

Partnership for 21st Century Learning (2015). P21 Framework Definitions. http://www.p21.org/our-work/p21-framework adresinden alınd1.

Peeters, H., and Lievens, F. (2005). Situational judgment tests and their predictiveness of college students' success: The influence of faking. Educational and Psychological Measurement, 65(1), 70-89. doi: $10.1177 / 0013164404268672$

Schmitt, N., Oswald, F. L., Kim, B. H., Imus, A., Merritt, S., Friede, A., and Shiypuri, S. (2007). The use of background and ability profiles to predict college student outcomes. Journal of Applied Psychology, 92, 165-179.

Selçuk, Z., Palancı, M., Kandemir, M. ve Dündar, H. (2014). Eğitim ve bilim dergisinde yayınlanan araştırmaların eğilimleri: İçerik analizi. Eğitim ve Bilim, 39(173), 430-453.

Soland, J., Hamilton, L. S., and Stecher, B. M. (2013). Measuring 21st century competencies guidance for educators. Santa Monica, CA: RAND Corporation.

Taş, U. E., Arıc1, Ö., Özarkan, H. B. ve Özgürlük, B. (2016). PISA 2015 ulusal raporu. Ankara: Milli Eğitim Bakanlığı. http://pisa.meb.gov.tr/wpcontent/uploads/2016/12/PISA2015 Ulusal Rapor1.pdf adresinden alınd1.

Trilling, B. and Fadel, C. (2009). 21st century skills: Learning for life in our times. Francisco: Jossey-Bass.

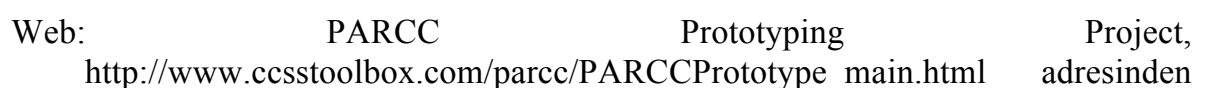
alındi. 


\title{
$21^{\text {st }}$ Century Skills and Tools and Approaches That Are Used to Measure These Skills
}

\begin{tabular}{lccc}
\hline ARTICLE TYPE & Received Date & Accepted Date & Online First Date \\
Review Article & 12.03 .2017 & 03.14 .2018 & 03.15 .2018 \\
\hline
\end{tabular}

\section{Seher Yalçın iD ${ }^{1}$}

Ankara University

\begin{abstract}
In this study, it is aimed to describe the 21 st century skills and to present various tools and approaches that are used to measure them. Along with containing basic skills, the 21 st century skills are seen to be composed of three main skill fields as: i) learning and innovation skills, ii) knowledge, media and technology skills, and iii) life and career skills. In the literature review, it is seen that in the measurement of such skills; rating scales, situational judgement tests, performance evaluation and simulations, portfolios, tools containing different types of item (such as multiple choice, computer-based and open response items) can be used. However, some of the mentioned measurement tools and approaches are not used in Turkey. Furthermore, in parallel with technological developments, it is seen that numerous countries started to use computer-based measurement applications. The computer environment allows the use of applications such as computer simulations based on real-life situations from these approaches, which allows both cognitive and interpersonal skills to be measured in a way that is very closely to reality. Moreover, it is suggested that measurement approaches such as the situational judgment tests which will enable students to demonstrate their interpersonal and intrapersonal skills must be given in the textbooks.
\end{abstract}

Keywords: 21st century skills, measurement, situational judgment tests, computer-based applications.

\footnotetext{
${ }^{1}$ Corresponding Author: Res. Asst. Dr., Faculty of Educational Sciences, Department of Educational Sciences, E-mail: yalcins@ankara.edu.tr, http://orcid.org/0000-0003-0177-6727
} 


\begin{abstract}
Summary

\section{Introduction and Purpose}

In this study, it is aimed to describe the $21^{\text {st }}$ century skills and to present various tools and approaches that are used to measure them. Along with containing basic skills such as reading, mathematics, and science the $21^{\text {st }}$ century skills is seen to be composed of three main skill fields as: i) learning and innovation skills, ii) knowledge, media and technology skills, and iii) life and career skills (Kylonen, 2012; Partnership for $21^{\text {st }}$ Century Learning, 2007; Trilling and Fadel, 2009). Being among these main skills, learning and innovation skills are composed of four skills as; i) critical thinking and problem solving, ii) communication, iii) collaboration, and iv) creativity. Knowledge, media and technology skills include: i) knowledge, ii) media, and iii) information and communication technologies literacy. As for life and career skills, they consist of i) flexibility and compatibility, ii) initiative and selfmanagement, iii) social and intercultural interaction, iv) productivity and accountability, and v) leadership and responsibility skills (Kylonen, 2012; Partnership for $21^{\text {st }}$ Century Learning, 2007; Trilling and Fadel, 2009).
\end{abstract}

\title{
Discussion and Result
}

The measurement and evaluation of the $21^{\text {st }}$ century skills may require approaches that are different from the evaluation approaches used thus far. For example, short, structured response or essay tests may be inadequate in measuring interpersonal skills such as; teamwork, cooperation, leadership and communication, or some difficult cognitive skills such as creativity (Kylonen, 2012). In the literature review, it is seen that in the measurement of such skills; rating scales, situational judgement tests, performance evaluation and simulations, portfolios, multiple choice items, computer based items and open response items can be used (Kylonen, 2012; Soland et al., 2013). However, it is seen that some of the mentioned measurement tools or approaches are not used in Turkey. Furthermore, in parallel with technological developments, numerous countries started to use computer-based measurement applications. With the progress in computer technology and the widespread use of the internet, information regarding the skill and ability history that is acquired from social media and computer simulations (Kylonen, 2012; Schmitt et al., 2007) and computer based items are perceived to become widespread in measurement applications (OECD, 2017; Soland et al., 2013). In the measurement of cognitive skills; approaches such as performance evaluations and simulations, multiple choice, computer based, and open response items can be used. Likert type items, situational judgment tests, performance evaluations and simulations, portfolios and multiple choice items can be used in measuring of interpersonal skills. In the measurement of intrapersonal skills, items and approaches such as likert type items, situational judgment tests, biodata and portfolios can be used.

With technological developments, knowledge and skills that students need to obtain are increasing while the measurement and evaluation approaches are 
changing. In this context, teachers and prospective teachers should be provided with training regarding identifying students' 21 st century skills and approaches (tools, item types, etc.) that they can use to measure these skills. Moreover, computer environment allows the use of applications such as computer simulations based on real-life situations, which allows both cognitive and interpersonal skills to be measured in a way that is very closely to reality. In this context, in parallel with technological developments, it is suggested that by benefiting from the advantages that computer-based systems offer, Minister of National Education may start carrying out measurement and evaluation applications on the basis of computer based system. 